Twenty-six suggested diagnoses were given, and of these:-

6 were confirmed by microscope.

10 others were confirmed by the clinical history.

In 5 the clinical history was doubtful, and confirmation of the diagnosis is lacking.

In 5 our diagnosis was probably wrong.

Thus there were 52 confirmed diagnoses of amobic or bacillary dysentery, and there were 6 cases in which the symptoms were caused by other local conditions, such as hæmorrhoids, \&c.

Of the remaining 43 cases:-

11 were undiagnosed.

11 appeared normal, and of these :-

In 1 the clinical history was doubtful.

6 had no symptoms and were discharged.

1 had Entamoba histolytica eysts and a liver abscess, but had never had dysentery.

2 had Entamoba histolytica cysts in their stools.

3 gare a history of amobic dysentery.

1 ,

,

In jock confirmation.

In other words, the sigmoidoscope was instrumental in giving a positive diagnosis - that is, a confirmed diagnosisfrom a single examination in just 58 per cent. of our cases, while in the same 100 cases microscopic diagnosis, afterrepeated tests, gave about 30 per cent.

In conclusion. we wish to express our indebtedness to Dr. G. C. Low for generously permitting us to utilise figures obtained from cases under his care. Many of the routine microscopical examinations of fæces so frequently quoted in this paper were undertaken by Dr. J. Gordon Thomson, whom we also wish to thank for his assistance, as well as for his kind permission to reproduce his excellent microphotograph of Charcot-Leyden crystals (Fig. 4).

References made in Text.-1. Bencaude, R.: Rectoscopie et Sigmoidoscopie, Nasson et Cic., 1919, p. 35. 2. Lyons, R. : Southern Nedical Journal, vol. xiii., No. 1, Jan. 1920 , p. 6. 3. Dobell, . : Medical Research Council, Special Report Series, 1920, No. 51, p. 69. 4. Dobell, C. : National Health Insurance Special Iieport Series, 1917, No. 4, p. 28. 5. Dobell, C.: Medical Research Council, Special Report Series, 1921 , No. 59, p. 41. 6. Thomson, J. G., and Hirst, L. F. : Reports from the Patho logical Laboratories at No. - General Hospital, Alexandria, THE LANCET, 1918, ij., p. 448. 7.Acton, H. W.: The Significance of Charcot-Ieyden Crystals in the Freces as an Indication of Amobic Colitis, 1918, Indian Jonrnal of Medical Research October, vol. vi., No. 2, pp. 1.̃.7-161. 8. Manson-Bahr,
Journal R.A.M.C., vol. xxxii., No.2, August, 1919, p. 136.

\section{A METHOD OF OPERATION FOR THE}

\section{TREATMENT OF ECTOPIA VESICA.}

\section{BY CH.ARLES ROBERTS, M.B., B.S. LOND.} F.R.C.S. ENG.,

HON. SURGEON, MANCHESTER ROYAL INFIRMARY; CONSUITLYG HON. SURGEON, MAXCHESTER CMLDREN'S HOSPITAL, PEXDLEBURT.

THE modern treatment for ectopia vesicæ is to divert the ureters into the bowel. The trigone of the bladder may be transplanted into the sigmoid colon by the intraperitoneal route (Madyl, Stiles, Coffey), or the ureters may be transplanted into the rectum by the extraperitoneal route (Peters, Moynihan). I wish to describe a method of operation which I have employed in four cases of ectopia vesicæ with very satisfactory results.

\section{Method of Operation, Advantages, and Age at which} it should be Performed.

The operation consists briefly in transplanting the ureters directly into the rectum through its anterior wall above the level of the peritoneal reflection of Douglas's pouch, the general peritoneal cavity being: shut off by suture before opening the bowel.

The operation is very simple to perform and can be completed in less than 30 minutes, thus involving little or no shock. It avoids the risk of infective peritonitis, owing to occasional leakage of the intraperitoneal operation, and the danger of subsequent retraction of the ureters into the bladder wound of the extraperitoneal method.
The operation should be postponed until the child attains the age of 2 years when the anatomical structures are large enough to facilitate the necessary dissection, manipulation, and suturing, and when the after-treatment can be carried out with greater satisfaction.

\section{Preliminary Treatment.}

Hexamine and acid sodium phosphate in suitable doses are administered to minimise the risk of ascending pyelitis. Occasionally after operation the child suffers from attacks of pyrexia accompanied by vomiting, irritability, and drowsiness, probably due to infective pyelitis. These attacks are liable to recur but tend to diminish gradually and can be controlled by giving urinary antiseptics. The skin is prepared in the usual way and the rectum is cleansed by frequent irrigation. The exact position of the ureters should be determined in order to avoid delay at the time of operation, as the orifices may lie rather concealed in folds of mucous membrane.

\section{Description of the Operation.}

The pelvis is raised on a small sandbag. I prefer to stand on the left side of the patient. After passing a small probe, a No. 2 Black French catheter (the end of which has been removed to leave a terminal opening) is inserted $\mathrm{into}$ each ureter for a distance of from 2 to 3 inches, and is sutured in position by a fine catgut suture inserted with a fine straight needle which transfixes the catheter and the bladder mucous membrane at a distance of 1 inch from the summit of the ureteral papilla.

The mucous membrane is then incised circularly at a distance of 1 inch from the orifice of the ureter and the incision is carefully carried through the bladder wall until the wall of the ureter is reached. Great care must be taken

not to injure the ureter and its vessels. The ureter is freed by dry gauze dissection, and by snipping a few fibrous bands with scissors or scalpel, until about 2 inches of the ureter can be drawn into the wound (Fig. 1). The assistant then inserts a finger of the right hand into the rectum and presses its anterior wall into contact with the posterior wall of the bladder at a level well above the uterus, which can be readily felt in the female, and at a corresponding distance in the male. The bladder wall lying between the ureteral pouches is then incised transversely (Fig. 1) on to the assistant's finger until the peritoneal cavity is opened, when the anterior rectal wall at once protrudes through the incision thus made (Fig. 2).

Fine catgut sutures are passed through the cut edges of the bladder wall and the sero-muscular coat of the rectum so that an area of the anterior surface of the rectum measuring about $2 \mathrm{in.} \mathrm{by} 1$ in. is completely shut off from the general peritoneal cavity (Fig. 3). Through this area a transverse incision about $1 \frac{1}{2}$ inches long is made into the bowel whilst the assistant partially withdraws his finger (Fig. 3). The catheters are then passed through the opening, taken by the assistant, and carefully drawn from the anus until the ureters with their surrounding mucous membrane lie just within the rectum. The opening into the rectum is then closed with catgut sutures in such a manner that the ureters are fixed 
firmly at the angles of the wound (Fig. 4). The transverse incision in the bladder is sutured over this. No attempt is made to remove any of the bladder wall. This is better dealt with at a second operation.

\section{After-Treatment and Results.}

The ureteral catheters commence to drain within a few hours and become loosened within 5 or 7 days, sutures. The transplanted ureters readily accommodate themselves to their new anatomical relations, and development is not interfered with.

At the provincial meeting of the Section of Diseases of Children of the Royal Society of Medicine held in Manchester in July, 1920, I showed a patient on whom I had performed this operation in October 1908. The uterus appears normally developed and she
P.R.W.

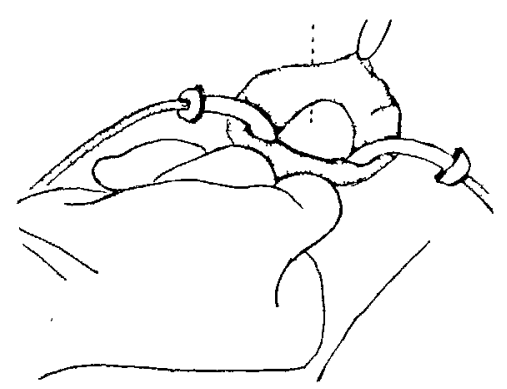

Fig. 2.-P.R.W., Pouch of anterior rectal wall pushed through bladder incision by finger in recturn.

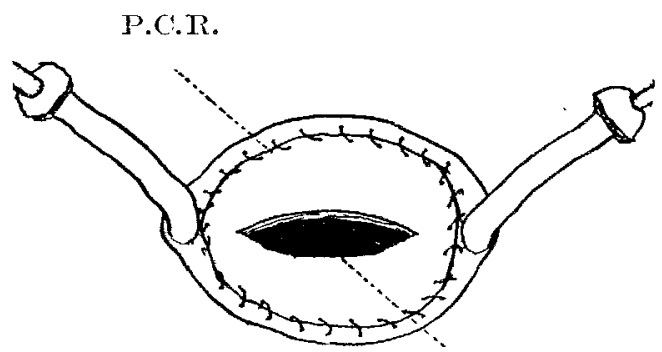

I.R.

FIG. 3.-P.C.R., Peritoneum covering of rectum stitched to peritoneum covering
of bladder ; I.R., Incision into rectum.

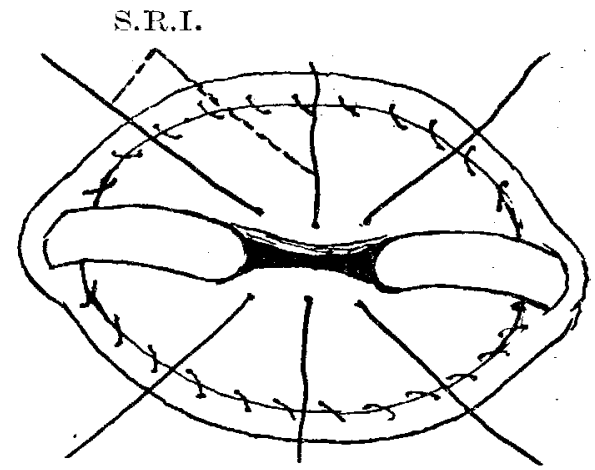

FIG. 4.- Ends of ureters inserted into rectum. S.R.I., Sutures closing rectal incision.

when they are withdrawn. If either catheter ceases $\mid$ menstruates regularly. The rectum carries out its to drain before this it must be removed and can double function independently. Freal evacuation easily be loosened by twisting movements, traction usually occurs once daily and urine is voided sepabeing avoided. Hexamine and acid sodium phosphates are given for the reasons previously mentioned.

About six months later the mucous membrane of the bladder is excised and the raw surfaces brought together by under-running strong silkworm-gut rately, three or four times by day and not at all during the night. The diagrams have beea made from phatographs taizen during an operation, and I am much indebted to Dr. W. E. Fothergill, who has kindly drawn them for me.

\section{OBSERVATIONS ON THE \\ UREA CONCENTRATION TESTS IN THE PSYCHOSES.}

BY J. WALKER, M.B., CH.B.EdiN., D.P.H., SENIOR ASSISTANT MEDICAL OFFICER, CARDIFF CITY MENTAL HOSPITAI, WHITCHURCH, GLAM.

THE primary objects of this investigation were to dis cover if there is any undue prevalence of renal in efficiency in the psychoses, as determined by the urea concentration tests in the blood and urine, and, if so, with what forms of mental disorder this condition is associated. During the progress of the investigation it was observed that several cases showed a low urea concentration in the urine with either a normal or subnormal blood concentration. It was therefore thought desirable to estimate the daily excretion of urine with the total excretion of urea and ammonia and the percentage urea concentration in the same. The urea nitrogen and ammonia nitrogen ratio was also determined.

Concentration Tests in the Blood and Urine.

The tests employed were those described by H. MacLean and A. E. Russell, ${ }^{1}$ and their instructions as to diet, \&c., prior to the tests were strictly adhered to. The urine test commenced at $10 \mathrm{~A} . \mathrm{M}$.- - i.e., about $2 \frac{1}{2}$ hours after a breakfast consisting of bread, butter and tea. The patient was then put to bed and no further fluid permitted until the completion of the test. Printed instructions were issued on the occasion of every test. The blood was withdrawn between $11.30 \mathrm{~A}$.M. and 12 mid-day-i.e., at the corresponding time, but either on the day prior to or following the urine test. Sufficient blood was always collected to enable a duplicate examination to be made, the average of the two estimations being taken as a measure of the urea concentration. The tests were repeated in a few cases, but as the results were more or less the same it was not considered necessary to do this in all cases.

Prior to and during the collection of a 24-hour specimen each patient received a fixed diet consisting of two pints milk, two eggs, milk pudding, with bread- and-butter. The total excretion of ammonia was estimated by the formalin method. Albumin in all cases was tested for by the salicyl-sulphonic acid and heat tests. The systolic blood pressure was determined during the clinical examination of each case.

Before the results obtained in this investigation are considered, it is necessary to have a clear understanding as to what are considered the normal limits of ureaconcentration in the blood and urine. In spite of the fact that W. MacAdam and Bentley Squire ${ }^{2}$ give the maximum blood concentration of $25 \mathrm{mg}$. and $12.5 \mathrm{mg}$. per cent. respectively, I consider that MacLean's maximum of $40 \mathrm{mg}$. per cent. is none too high. In Tables I. and II. are cases with a much higher blood concentration with a urine concentration not only between the normal limits of 2 and 4 per cent. as set out by MacLean, but even greater than 4 per cent. Clinical as well as other evidence was contrary to a diagnosis of renal disease in each of those cases. The lowest and highest percentage concentration of urea in the blood found by me in cases showing no evidence of renal disease are $9 \mathrm{mg}$. and $83 \mathrm{mg}$. per cent. respectively. But basing my result on the normal standard percentages by MacLean-viz., 15 to $10 \mathrm{mg}$. per cent. in the blood and 2 to 4 per cent. in the urine, $I$ find there is a large percentage of cases giving abnormal results in which the diagnosis of renal disease, apart from the tests referred to, is not justified.

Eighty-three cases have been investigated. Table III. gives these cases grouped according to their mental disorder with the findings in each. It is seen that 36 per cent. have a normal urea concentration in the blood and urine, according to the limits referred to above. This is a very low percentage. If the cases showing a normal blood concentration with a urine urea concentration below 2 per cent. in which the low urine concentration appears to be due to diuresis, that is, when the total urine excreted in the first and second hours together exceed $350 \mathrm{c.cm}$.-this diuresis is especially frequent in dementia præcox, and will be discussed later-are considered for the present to be consistent with a healthy condition of the kidneys, the percentage of normal cases is raised to 52. Again, if cases with a normal urine concentration and a blood concentration below $15 \mathrm{mg}$. per cent. are included for the same reason, the percentage of normal cases is raised to 57 . Of the 43 per cent. of the cases remaining 